\title{
Anaesthetic Management of Cytoreductive Surgery with Hyperthermic Intraperitoneal Chemotherapy (CRS/HIPEC): A True Challenge To an Anaesthetist
}

\author{
Dr. Roly Mishra $^{1^{*}}$ | Dr.Kritika Sharma ${ }^{2}$ | Dr Jueeli Barpande ${ }^{3}$ | Dr Nitu Kumari ${ }^{4}$ Dr. \\ Hemant Mehta ${ }^{5}$
}

1(MBBS) Netaji Subhash Chandra Bose Medical
College And Hospital, Tilwara Road,
Jabalpur-482003, (M.P) India
(Third Year Dnb Resident) Department Of
Anaesthesia And Pain Managemnent
Sir H N Reliance Foundation Hospital And
Research Centre, Prarthana Samaj, Girgaon,
Mumbai-400004 (Maharshtra) India

${ }^{2}$ (MBBS) Kasturba Medical College,Manipal University,Magalore- 575001 (Karnataka) India (DNB) Narayana Institute Of Cardiac Sciences, Bommasandra Industrial Area,Bengaluru- 560099 (Karnataka) India

(CLINICAL ASSOCIATE) Anaesthesia And Pain Managemnent Sir H N Reliance Foundation Hospital And Research Centre Prarthana Samaj Girgaon, Mumbai-400004 (Maharshtra) India

${ }^{3}$ (MBBS) MGM Medical College And Hospita Gate No. 2 Mgm Campus N-6 Cidco, Aurangabad 431003(Maharashtra) India

(MD) Department Of Anaesthesia And Pain Management, Kem Hospital And Sgs Medical College, Mumbai-400012 (Maharashtra) India (EUROPEAN DIPLOMA IN ANAESTHESIA AND INTENSIVE CARE SENIOR CONSULTANT) Anaesthesia And Pain Managemnent Sir $\mathrm{H} N$ Reliance Foundation Hospital And Research Centre Prarthana Samaj, Girgaon, Mumbai-400004 (Maharshtra) India

4(MBBS) MGM Medical College Dimna Road ,Hill View Colony , Mango, Jamshedpur-831020 (Jharkhand) India

(DNB) Anaesthesia-Tata Motors Hospital,Telco Colony,Jamshedpur-831004, (Jharkhand) India (CLINICAL ASSOCIATE) Anaesthesia And Pain Managemnent Sir H N Reliance Foundation Hospital And Research Centre Prarthana Samaj Girgaon, Mumbai-400004 (Maharshtra) India

${ }^{5}$ (MBBS, MD, DA) Department Of Anaesthesia And Pain Management, Kem Hospital And Sgs Medical College, Mumbai-400012 (Maharashtra) India (DIRECTOR AND HEAD) Anaesthesia And Pain Managemnent Sir H N Reliance Foundation Hospital And Research Centre Prarthana Samaj, Girgaon, Mumbai-400004 (Maharshtra) India

\section{Abstract:}

Patients diseased with gynecological malignancies were believed untreatable with poor survival chances till hyperthermic intraperitoneal chemotherapy after capital cytoreductive surgery came into existence. Perioperative management of this patient, for a major surgery like $\mathrm{CRS} / \mathrm{HIPEC}$ is complex and challenging. Major perioperative concerns in these patients include anesthetic challenges intraoperative fluid management, maintaining mean arterial blood pressure, thermoregulation electrolyte imbalances, significant blood loss and fluid shifts and renal toxicity after chemotherapeutic drugs administration. We report a case of 66 year old female diagnosed with carcinoma ovary with moderate ascites posted for cytoreductive surgery and HIPEC.

Keywords: Gynaecological malignancy, cytoreductive surgery, hyperthermic intra peritoneal chemotherapy, peritoneal carcinomatosis

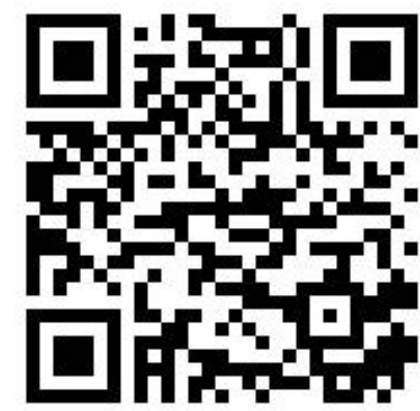




\section{1 | INTRODUCTION:}

$\mathrm{P}$ atients suffering from gynaecological neoplasms, resulting in peritoneal carcinomatosis, have a high morbidity and poor quality of life $[1,2]$ The current treatment method available for patients with local cancer spread with the absence of distant metastases includes cytoreductive surgery and the continuous hyperthermic peritoneal perfusion with chemotherapeutic agents [3]. There are innumerable perioperative concerns in these patients which include optimal fluid management, maintaining mean arterial blood pressure, temperature management, coagulation and electrolyte derangement and renal toxicity of chemotherapeutic drugs.

\section{I CASE REPORT:}

This case report describes a 66 year old, hypertensive and asthmatic patient, on regular treatment for the same, diagnosed with carcinoma ovary who was submitted to cytoreductive surgery (CRS) and hyperthermic intraperitoneal chemotherapy (HIPEC), under general anaesthesia combined with a non-continuous epidural block after six cycles of chemotherapeutic drugs namely Pacliaqualip and Carboplatin.

On general and systemic examination, no significant abnormality was noted. Preoperative investigations were performed in which all routine blood investigations were normal. Chest $\mathrm{x}$-ray showed increased Broncho vascular markings and ECG was normal. 2D ECHO showed LVEF 60\% with no regional motion wall abnormality and mild diastolic dysfunction. Pulmonary function test were indicative of moderate obstructive ventilator defect with poor reversibility post bronchodilator. The diffusion capacity was severely reduced with reduced transfer coefficient. Our patient received Salbutamol and Budecort nebulisation twice a day with Foracort 400 inhaler twice a day as prescribed by the chest physician.

The patient was taken inside the operating theatre after ensuring adequate fasting, presenting with a moderate ascitic abdomen. A well written detailed Informed Consent was taken from the patient and her relatives. They were counselled well regarding the expected intraop-complications like significant blood loss and injury to adjoining vessels and organs, post op prolonged ICU stay and sos mechanical ventilation. All emergency drugs including phenylephrine, adrenaline, antiarrhythmic drugs, noradrenaline infusion and defibrillator pads were kept ready. All necessary drugs and equipment for General anaesthesia were kept ready. The patient was optimally monitored with electrocardiogram, noninvasive blood pressure, and pulse oximetry. In the operating room, the baseline heart rate was noted to be 103 beats per minute and, the blood pressure was 146/92 mmhg and 96\% spo2. Two large venous lines in the upper limbs were secured. The patient was coloaded with ringer lactate. Subsequently, the patient was given sitting position for an epidural block in T9-T10 using $16 \mathrm{~g}$ tuohy needle epidural set, epidural catheter was inserted in T7-8 space under all aseptic precautions.

Right radial artery was cannulated under local anaesthesia for beat to beat blood pressure monitoring. Central line was secured in right internal jugular vein under USG guidance with local infiltration under all aseptic precautions for CVP monitoring.

A balanced general anesthesia was induced with $100 \mu \mathrm{g}$ of Fentanyl, $25 \mathrm{mg}$ of Lidocaine, $120 \mathrm{mg}$ of propofol and $50 \mathrm{mg}$ of Atracurium. Then, the monitoring was complemented with an oesophageal thermometer was used as muscle relaxant. Patient was intubated with 7 no. Portex endotracheal tube and it was fixed at $20 \mathrm{~cm}$ at the angle of the mouth after confirming bilaterally equal air entry. Ryle's tube no 14 FG was inserted, position confirmed on auscultation. Eyes were taped and padded. Anaesthesia was maintained with air+oxygen + Desflurane with target MAC of 1.1 and Infusion Atracurium

Supplementary information The online version of this article (https://doi.org/10.15520/jcmro.v3i07.307) contains supplementary material, which is avaiable to authorized users.

Corresponding Author: Dr. Roly Mishra

Third year DNB Resident Anaesthesia and Pain Management Sir H N Reliance Foundation Hospital and Research Centre

Email: rolymishra031@gmail.com 


\section{ANAESTHETIC MANAGEMENT OF CYTOREDUCTIVE SURGERY WITH HYPERTHERMIC INTRAPERITONEAL CHEMOTHERAPY (CRS/HIPEC): A TRUE CHALLENGE TO AN}

ANAAESTHET 5 S $\mathrm{mg} / \mathrm{kg} / \mathrm{hr}$ for muscle relaxation.

We ensured that DVT stockings were applied on the patient as a measure to prevent deep vein thrombosis. Body temperature ranged between $34.6{ }^{\circ} \mathrm{C}$ and 36.6 ${ }^{\circ} \mathrm{C}$. During the cytoreduction. when the abdominal cavity is open there is a paramount heat loss and severe hypothermia. To prevent that warming devices were made available beforehand (i.e., forced air warming, warmed infusions, hot blankets). During the HIPEC phase of the surgery as the warm infusate gets delivered inside the abdominal cavity, the temperature of the patient rises. Cold fluids, ice packs, cooling mattress were also kept prepared for the same. Our patient had pre-existing lung pathology, and it gets worsened during the surgery. We used lung protective strategy consisting of low tidal volume, optimal positive end expiratory pressure and recurrent recruitment manoeuvre's to prevent the respiratory derangements intra op.Inj. Tranexamic acid $20 \mathrm{mg} / \mathrm{kg}$ was administered along with the antibiotic prophylaxis before the surgical incision. Maintaining hemodynamics amongst blood and fluid shifts was extremely challenging. We kept an eye on hourly urinary output and continuous CVP and PPV.Inf. Albumin 20\% was continued during the surgery. Two units of PCV $(736 \mathrm{ml})$ along with four FFPS $(688 \mathrm{ml})$ were given to counter on going blood loss along with $3500 \mathrm{ml}$ of crystalloids. To maintain hemodynamic stability Inf.Noradrenaline support of $0.05 \mathrm{mcg} / \mathrm{kg} / \mathrm{min}$. was started. A continuous infusion of $0.125 \%$ Bupivacaine was continued throughout the surgery for pain control. Surgery lasted for 5 hours 20minutes. After the procedure the patient was shifted to ICU on mechanical ventilator for further monitoring and management with noradrenaline support of $0.03 \mathrm{mcg} / \mathrm{kg} / \mathrm{min}$. The inotropes were tapered and stopped over the next few hours. An epidural baxter of $0.125 \%$ bupivacaine and $2 \mathrm{mcg} / \mathrm{ml}$ Fentanyl was started for pain control.Also, she received Inj.Paracetamol round the clock for better pain management. On the post-operative day 1 , she was extubated.She had mild pain in the abdominal region. The postoperative period was uneventful otherwise. She evolved to leave the ICU after 48 hours hand was discharged from our institution on the $8^{\text {th }}$ postoperative day, without complaints. She comes now for a clinical follow up with the Oncology
Service.Figures 1, 2, 3 and 4

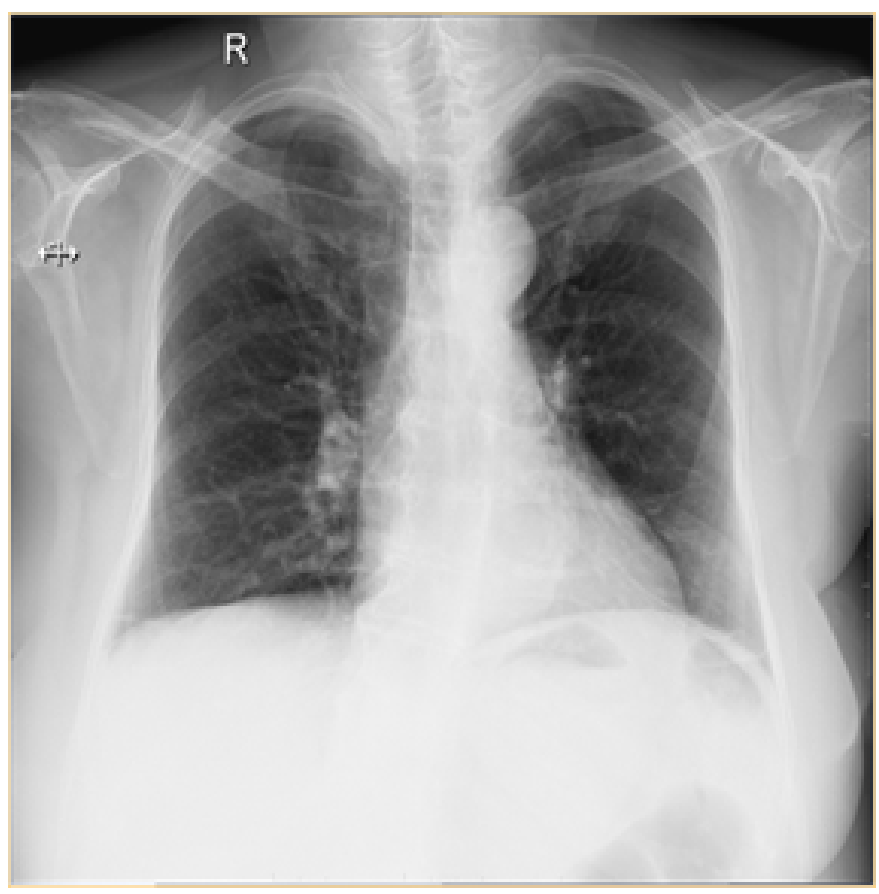

FIGURE 1: PREOPERATIVE CHESTXRAY

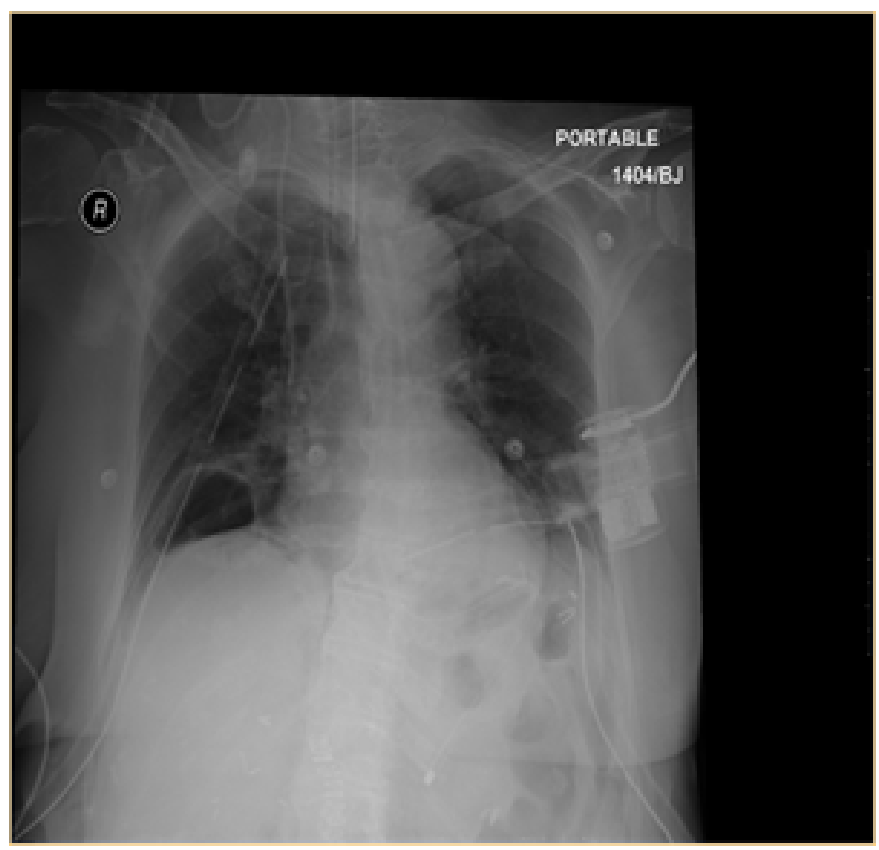

FIGURE 2: POSTOPERATIVE CHESTXRAY

\section{3 | DISCUSSION:}

Primary peritoneal neoplasm and metastasis to peritoneum from gynaecologic or gastrointestinal cancer 


\section{MANUSCRIPT CENTRAL}

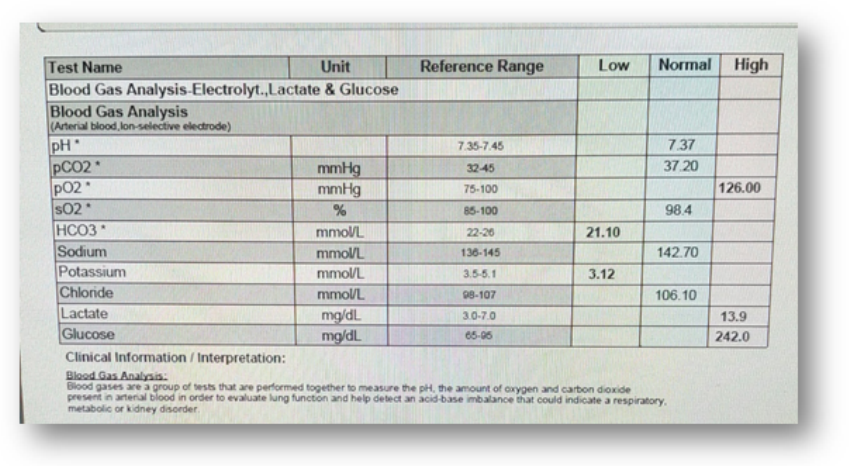

FIGURE 3: POSTOPERATIVE ABG

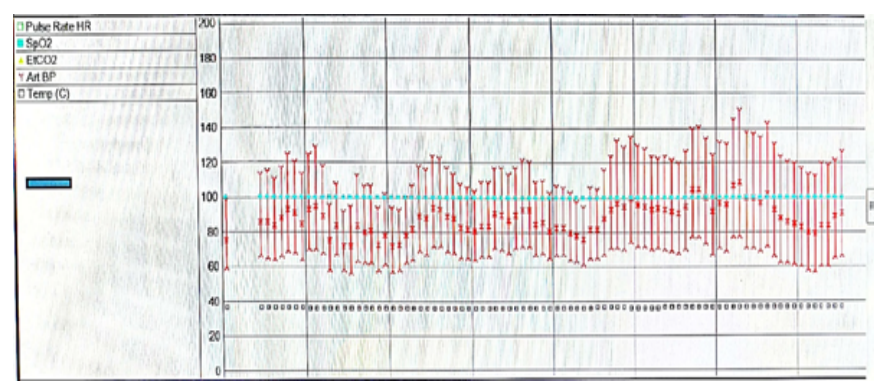

FIGURE 4: INTRAOPERATIVE VITALS

are associated with a very poor prognosis and were considered incurable for a long time, until, Dr Paul Sugarbaker showed that surgical removal of visible tumour for peritoneal mesothelioma combined with loco-regional heated chemotherapeutic drugs improved median survival of these patients. [4]

The surgery requires a full-length midline incision followed by cytoreduction involving removal of macroscopic tumour which can vary from omentectomy to resection of multiple organs depending on the spread. In our patient, resection included $\mathrm{BSOH}$, splenectomy, omentectomy, $+\mathrm{B} / \mathrm{L}$ diphragmatic \& anterolateral parietal peritoneum

This is followed by the final stage of chemoperfusion where the abdominal cavity is rinsed with a heated chemotherapy solution which can be done by the open (or Coliseum) or closed techniques. [5]

In our centre, we comply with the open approach which ensures gold standard distribution of heat and cytotoxic solution due to manual stirring of the abdominal contents; however, it is associated with; with heat loss which requires an increase in the temperature of the perfusion fluid, as well as the risk of spillage of cytotoxic drugs. [5, 6]

The closed method prevents heat loss associated with the open technique, minimizes drug spillage, and increases drug penetration, however homogeneous distribution of the perfusion fluid may now not be achieved [5, 6] . The HIPEC phase which can vary from 30 minutes to 2 hours is associated with several physiological changes including increase in heart rate, central venous pressure, peak airway pressures, end tidal $\mathrm{CO} 2$ levels, decrease in $\mathrm{PaO} 2 / \mathrm{FiO} 2$ ratio, decreased perfusion to kidneys and metabolic acidosis. The hyperthermia is also associated with coagulopathy with a decrease in platelet count and an increase in Prothrombin Time (PT) and International Normalised Ratio (INR).

Preoperative evaluation involves a thorough evaluation of the patient's cardiopulmonary systems to assess their ability to tolerate intraoperative physiological changes. Our patient was found to have moderate obstruction with poor reversibility post bronchodilator and severely reduced diffusion capacity on spirometry which posed significant challenges intraoperatively. Ovarian neoplasm is associated with malnutrition and hypoalbuminemia which is associated with pronged hospitalisation and increased complications.

Prehabilitation plays an important role in overall outcome which includes optimising the nutritional status, spirometry to improve lung function as atelectasis is common in these patients due to associated ascites and pleural effusion as well as giving prophylaxis for venous thromboembolism. Estimation of the glomerular filtration rate may help identify patients at risk of an acute kidney injury associated with the HIPEC. [7]

The degree of peritoneal disease is assessed by Peritoneal Cancer Index (PCI) score described by Dr Sugarbaker, which has a high prognostic value [4] . The PCI score in our patient was 29.

Cytoreduction is associated with significant blood loss and third space loss associated with peritoneal inflammation. Keeping in mind the large fluid shifts, fluid resuscitation with crystalloids, colloids i.e. albumin and blood and blood products was done to maintain end organ perfusion. We maintained PPV $<13$, MAP $>80 \mathrm{mmhg}$, haematocrit $>28$ and urine output more than $0.5 \mathrm{ml} / \mathrm{kg} / \mathrm{hr}$ during CRS phase and more than $2 \mathrm{ml} / \mathrm{kg} / \mathrm{hr}$ during HIPEC phase. 


\section{ANAESTHETIC MANAGEMENT OF CYTOREDUCTIVE SURGERY WITH HYPERTHERMIC INTRAPERITONEAL CHEMOTHERAPY (CRS/HIPEC): A TRUE CHALLENGE TO AN}

ANEAE patientS aPSO develop coagulopathy either during CRS or HIPEC phase which can be monitored by TEG. We gave Tranexamic acid 1 gram and also transfused four FFP s during the procedure. There is an association between the PCI score and risk of coagulopathy. [8]

A good pain control is important which can include thoracic epidural in the absence of coagulopathy, opioids, Paracetamol and other regional techniques like paravertebral block or subcostal TAP block.

During the CRS phase there is a risk of hypothermia due to extensive debulking and third space loss which further increases the risk of blood loss. We used warming blanket, forced air warmer and warm fluids to maintain normothermia. During the HIPEC phase the solution is heated to $42-43$ degree Celsius which can cause hyperthermia, which can cause an increase in oxygen demand, with rising end tidal CO2 levels and a concomitant metabolic acidosis.

Prior to commencement of HIPEC phase, we changed to cool intravenous fluids and decreased room temperature and switched off the forced air warmers in anticipation of the hyperthermia.

Thus, we should maintain normothermia by switching off the warming device and using the underbody mattress to cool the patient. Cold intravenous fluids and placing ice packs in the axillae of the patient may help to normalize the temperature.

Another challenge in our case was the obstructive pulmonary disease with severe diffusion defect which causes ventilation perfusion mismatch. It can cause air trapping and development of intrinsic PEEP which can lead to cardiovascular instability due to increased intrathoracic pressure. Perioperative beta blocker therapy and application of PEEP intraoperatively helped preventing any complications.

Thus, the perioperative management of CRS and HIPEC is complex and requires a team approach with extensive prehabilitation and optimization to ensure successful outcome and early recovery and discharge.

\section{4 | CONCLUSION:}

Cytoreduction with HIPEC has emerged as a major adjunct in the treatment of peritoneal surface cancers.
These cases are difficult to the anaesthetist because they are associated with huge blood loss, fluid shifts, gaseous disturbances and hypothermia throughout the resection with hyperthermia related complications all through the HIPEC procedure.Authors thereby suggest adequate preparation, pre-operative optimisation, close monitoring and prompt intervention with multidisciplinary approach for better management of these patients.

Conflicts of Interest: The authors declare there were no conflicts of interest.

Funding: There is not any sources of funding.

\section{Ethical Approval:}

This is a case report. Approval by ethics committee was not required.

\section{REFERENCES}

[1] Raspe C, Piso P, Wiesenack C, Bucher M. Anesthetic management in patients undergoing hyperthermic chemotherapy. Current Opinion in Anaesthesiology. 2012;25(3):348-355. Available from: https://dx.doi.org/10.1097/aco. 0b013e32835347b2.

[2] Mendonça FT, Guimarães MM, de Matos SH, Dusi RG. Anesthetic management of Cytoreductive Surgery and Hyperthermic Intraperitoneal Chemotherapy (CRS/HIPEC): The importance of hydro-electrolytic and acid-basic control. International Journal of Surgery Case Reports. 2017;38:1-4. Available from: https://dx.doi.org/ 10.1016/j.ijscr.2017.07.011.

[3] Miao N, Pingpank JF, Alexander HR, Royal R, Steinberg SM, Quezado MM, et al. Cytoreductive Surgery and Continuous Hyperthermic Peritoneal Perfusion in Patients with Mesothelioma and Peritoneal Carcinomatosis: Hemodynamic, Metabolic, and Anesthetic Considerations. Annals of Surgical Oncology. 2009;16(2):334344. Available from: https://dx.doi.org/10.1245/ s10434-008-0253-z. 


\section{MANUSCRIPT CENTRAL}

[4] Hurdle H, Bishop G, Walker A, Moazeni A, Paloucci EO, Temple $\mathrm{W}$, et al. Coagulation after cytoreductive surgery and hyperthermic intraperitoneal chemotherapy: a retrospective cohort analysis. Canadian Journal of Anesthesia/Journal canadien d'anesthésie. 2017;64(11):1144-1152. Available from: https: //dx.doi.org/10.1007/s12630-017-0952-7.

[5] Halkia E, Tsochrinis A, Vassiliadou DT, Pavlakou A, Vaxevanidou A, Datsis A, et al. Peritoneal Carcinomatosis: Intraoperative Parameters in Open (Coliseum) versus Closed Abdomen Hipec. International Journal of Surgical Oncology. 2015;2015:1-6. Available from: https://dx.doi.org/10.1155/2015/610597.

[6] Sadeghi B, Arvieux C, Glehen O. Peritoneal carcinomatosis from non-gynecologic malignancies: results of the EVOCAPE 1 multicentric prospective study. Cancer. 2000;88(2):358-363.
[7] Nchez AAS, Ndez FJMF, Oz-Casares FCM. Peritoneal metastases of colorectal origin treated by cytoreduction and HIPEC: an overview. World J Gastrointest Oncol. 2014;6(10):407412.

[8] Silva R, R C, Ruiz M, Estevez FJ, B I. Are there intra-operative hemodynamic differences between the Coliseum and closed HIPEC techniques in the treatment of peritoneal metastasis? A retrospective cohort study. World $\mathrm{J}$;.

How to cite this article: Mishra D.R., Sharma D.K., Barpande D.J., Kumari D.N., Mehta D.H. Anaesthetic Management of Cytoreductive Surgery with Hyperthermic Intraperitoneal Chemotherapy (CRS/HIPEC): A True Challenge To an Anaesthetist . Journal of Current Medical Research and Opinion. 2020;503-507. h ttps://doi.org/10.15520/jcmro.v3i07.306 